\title{
Thyroid dysfunction in patients with diabetic retinopathy
}

\author{
Magdalena M. Stefanowicz-Rutkowska, Angelika Baranowska-Jurkun, Wojciech Matuszewski, \\ Elżbieta M. Bandurska-Stankiewicz
}

Clinical Department of Endocrinology, Diabetology, and Internal Diseases, School of Medicine, Collegium Medicum, University of Warmia and Mazury in Olsztyn, Poland

\begin{abstract}
Thyroid disease and diabetes mellitus (DM) are the most common endocrinopathies in clinical practice that interact with each other. On the one hand, thyroid hormones regulate carbohydrate metabolism and pancreas functions, and on the other hand DM affects the function and work of the thyroid gland. Diabetic retinopathy (DR) is a highly specific neurovascular complication of both type 1 and type 2 $\mathrm{DM}$, which is a significant cause of vision loss on a global scale. In DM, the internal blood-retinal barrier is the earliest to be damaged, and changes in neuroretina result from the loss of its adaptation to metabolic disorders. Patients with DM have a higher incidence of thyroid disease compared to people without DM. The coexistence of DM with thyroid disease leads to endothelial damage, and the degree of its dysfunction has a significant impact on the course of macro- and microangiopathic complications in patients. There are few reports in the literature about the impact of thyroid disease and substitution of levothyroxine preparations on the development and course of DR in patients with DM. It is unknown whether the fact that patients with unrecognised hypothyroidism are not treated with levothyroxine preparations disrupts thyroid hormone homeostasis to the extent that it may contribute to a higher incidence of DR. This review discusses recent clinical trials for thyroid dysfunction in patients with DR. (Endokrynol Pol 2020; 71 (1): 176-183)
\end{abstract}

Key words: thyroid disease; diabetes mellitus; diabetic retinopathy

\section{Introduction}

Thyroid disease and diabetes mellitus (DM) are the two most common endocrinopathies [1,2]. Thyroid hormones regulate basic life processes centrally and peripherally $[3,4]$. The connection between DM and thyroid disorders is characterised by a complex interaction. Undiagnosed thyroid dysfunction can negatively affect DM and its complications [5]. Microvascular complications of DM (retinopathy, nephropathy, and neuropathy) are increasingly important causes of morbidity and mortality, and care for affected patients contributes to burgeoning healthcare costs [6]. Diabetic retinopathy (DR) is a highly specific neurovascular complication of both type 1 and type $2 \mathrm{DM}$, which is a significant cause of vision loss on a global scale $[7,8]$. The increased risk of blindness among DM patients is a huge clinical problem. There are only a few reports in the literature in which the effects of thyroid disease, including autoimmune thyroid diseases (AITD) and substitution of levothyroxine preparations, on the development and occurrence of DR have been demonstrated. This review discusses recent clinical trials for thyroid dysfunction in patients with diabetic DR. Articles and their references were assessed and included as deemed relevant by the authors.

\section{Autoimmune thyroid disease}

Autoimmunity is the body's immune response directed against its own antigen or group of antigens. The emergence of autoimmune diseases is influenced by the interaction of causative factors (environmental factors, including infections), inheritance of sensitising genes, autoantigens, intrinsic antigen tolerance disorders, and apoptosis mechanisms [9]. Systemic connective tissue diseases result in emergence of autoantibodies that react with antigens throughout the body. Reaction with antigens specific only to a particular tissue causes organ-specific diseases, leading to disruption of physiological function and/or tissue damage of this organ $[9,10]$. The dynamics of an autoimmune disease is determined by antibody titres and the intensity of autoreactive T lymphocyte responses [11]. Autoimmune diseases are characterised by a chronic course with periods of exacerbation and remission, and heterogeneity in terms of incidence, clinical symptoms, and their pathogenesis. Their incidence is constantly increasing, currently constituting about $5 \%$ of the global population, placing third in highly developed countries regarding the number of cases and mortality resulting directly and indirectly from these diseases (after cancer and cardiovascular diseases) [12, 13]. In

Magdalena M. Stefanowicz-Rutkowska, Clinical Department of Endocrinology, Diabetology, and Internal Diseases, School of Medicine,

Collegium Medicum, University of Warmia and Mazury in Olsztyn, Poland; e-mail: m.m.stefanowicz@gmail.com 
women, autoimmune diseases occur more often than in men, constituting $\sim 78 \%$, which may indicate the participation of sex hormones in their development [14]. There are more than 80 disease entities known whose peak incidence falls between the age of 40 and 50 years [12]. The thyroid gland is the organ in which autoimmune diseases develop most often [15]. Organ-specific autoimmune thyroid diseases (AITD) include Graves disease (GD) and chronic lymphocytic (autoimmune) thyroiditis, or Hashimoto's thyroiditis (HT). Active CD4 lymphocytes, co-stimulating B lymphocytes for the production of anti-thyroid antibodies, participate in their pathogenesis. In HT, cytotoxic T cells destroy thyrocytes leading to hypothyroidism. In GD, active B lymphocytes produce antibodies that stimulate the thyroid-stimulating hormone receptor (TSHR) causing overproduction of thyroid hormones and hyperthyroidism [16]. The following thyroid hormone levels are used to monitor thyroid function and disease development: free thyroxine (fT4), free triiodothyronine (fT3), and pituitary hormone - thyroid-stimulating hormone (TSH); as well as titres of antithyroglobulin antibodies (ATA), including antithyroid peroxidase antibodies (aTPO), antithyroglobulin antibodies (aTG), and TSH receptor autoantibodies (anti-TSHR, TRAb) [17]. Hashimoto's thyroiditis is both the most common endocrine disease and the most common non-pathogenic cause of hypothyroidism $[15,18]$. HT is diagnosed on the basis of imaging and laboratory tests: ultrasounds of hypoechoic thyroid parenchyma, increased aTPO and/or aTG antibody titres, and increased TSH concentration. The ATPO antibody titre correlates with the number of autoreactive lymphocytes infiltrating the thyroid gland and the degree of its damage [19].

\section{Diabetic retinopathy}

Diabetic eye disease is a common term for vascular-related changes and all other types of eye complications caused by DM [7]. It is a highly specific neurovascular complication of both type 1 and type 2 DM. DR is a significant cause of vision loss on a global scale. In 2015, 415 million DR cases were diagnosed globally, and it is estimated that this number will increase to 642 million in 2040 [7, 8]. Neurovascular changes in the form of neurodegeneration were first discovered in 1960 in post-mortem examinations of patients with DM. The discovery of neurovascular changes in the retina in DM patients began the era of research on damage to the neural part of the retina [20-22]. The retina is a neural tissue $90 \%$ of which consists of neurons and glial cells (astrocytes and Müller cells) [23, 24]. Retinal pigment epithelium (RPE) together with Bruch's membrane (the inner part of the choroid) are involved in forma- tion of blood-retina barriers (BRB), which prevent the penetration of antigens and macromolecules from the choroid to the retinal space, the layer consisting mainly of photoreceptors [25]. In DM, the internal $\mathrm{BRB}$, consisting mainly of vascular endothelial cells, pericytes, and glial cells and forming a functional retinal neurovascular unit, is the earliest to be damaged $[23,24]$. Changes in neuroretina result from the loss of its adaptation to metabolic disorders accompanying DM [26]. Retinal neurodegeneration may overtake the microvascular changes characteristic of DR and play a role in its pathogenesis, but not in all diabetics [27].

Factors influencing the development of diabetic retinopathy are presented in Figure 1 [28].

Molecular mechanisms affecting retinal microcirculation disorders leading to BRB breakdown include inflammatory infiltrate, loss of pericytes, the kinin-kallikrein system, and vascular endothelial growth (VEGF) [28]. Vascular endothelial growth factor is the main factor regulating angiogenesis, stimulating proliferation and increasing the permeability of endothelial cells of veins, arteries, and lymphatic vessels. In 1994, Adamis et al. found increased expression of VEGF in ocular tissues in people with DR, and since then numerous studies have been conducted and published on the role of VEGF in diabetes-related diseases. It has been indicated that VEGF is responsible for neovascularisation and damage caused by excessive vascular permeability [29]. Risk factors for the development and progression of DR are, among others: duration of diabetes, metabolic imbalance of diabetes, hypertension, and lipid disorders [30]. The classic symptoms of DR include microaneurysms, haemorrhage, hard exudate (lipid clusters), cotton wool spots (due to retinal ischaemia), venous dilatation and beading, and intraretinal vascular abnormalities [31]. These symptoms can be assigned to two DR phases: non-proliferative diabetic retinopathy (NPDR) constituting the early phase of DR, and proliferative diabetic retinopathy (PDR), which is a severe degree of DR with an angiogenic response of the retina to its extensive ischaemia and capillary occlusion (with neovascularisation or/and intravitreal/epiretinal bleeding) $[32,33]$.

\section{Treatment of diabetic retinopathy}

The main and most important treatment of DR is to improve the metabolic control of diabetes, normalise blood lipids, and achieve recommended blood pressure [34]. Many studies on different populations demonstrated a significant increase in the prevalence of DR with increasing glycated haemoglobin $\left(\mathrm{HbA}_{1 \mathrm{c}}\right)$ levels [35-37]. Patients with DM1 who underwent intensive insulin therapy demonstrated that the risk of developing DR 


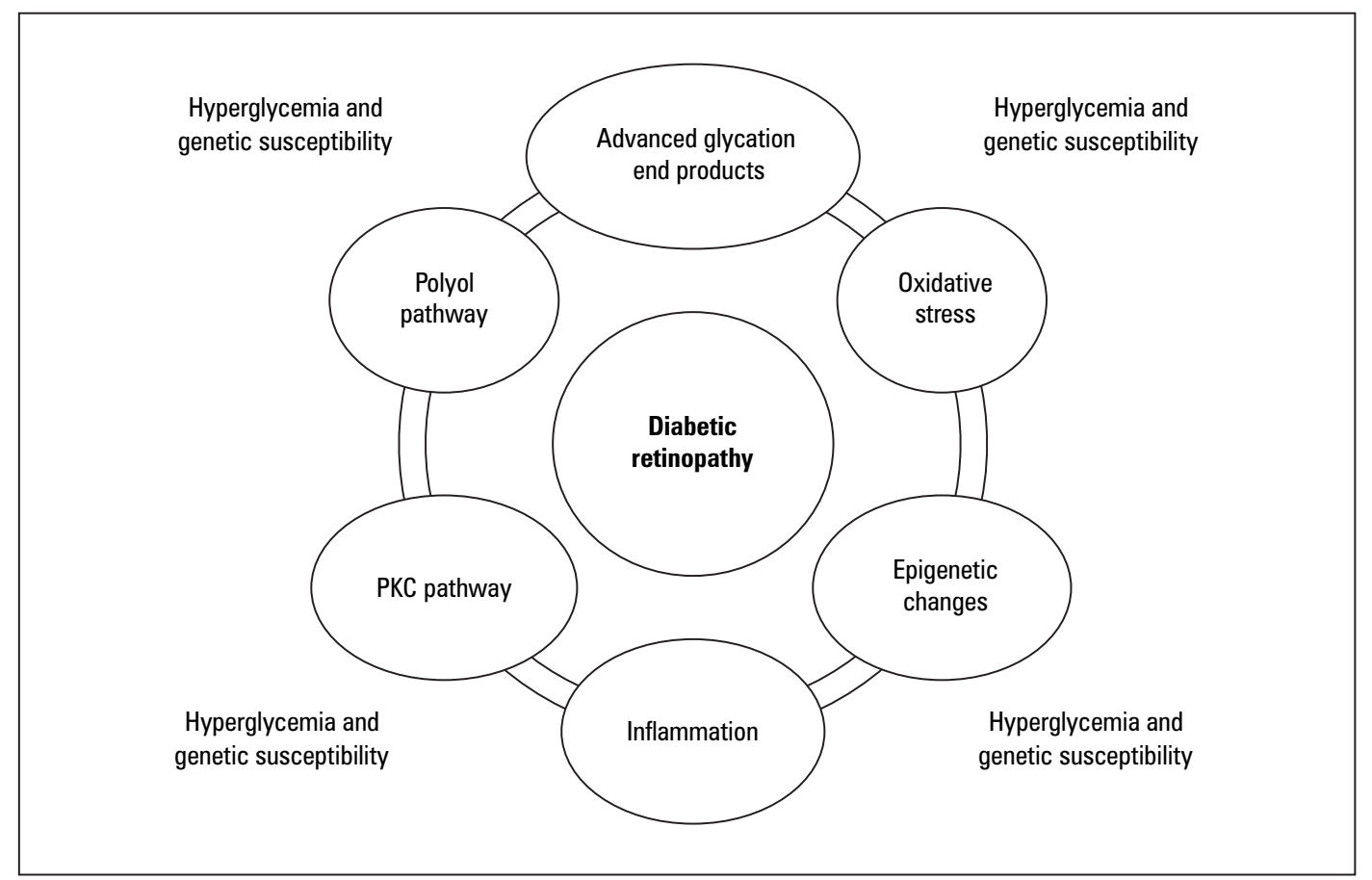

Figure 1. Factors influencing the development of diabetic retinopathy [28]. PKC — protein kinase C

was reduced by $76 \%$, and its progression was slowed by $54 \%$ [38]. In DM2 patients it was shown that the beneficial effect of intensive treatment reducing $\mathrm{HbA}_{1 \mathrm{c}}$ by $1 \%$ led to the reduction of DR progression by $21 \%$, and to a $30 \%$ reduction of the need for laser therapy. In the same study reducing systolic pressure by $10 \mathrm{mmHg}$ reduced the risk of microangiopathy, including DR, by $13 \%[39,40]$. They showed that it was not the particular anti-diabetic drug used, i.e. sulfonylurea or metformin or insulin, but the degree of glycaemic control that mattered for prevention of DR [39]. Intensive insulin therapy is a beneficial method of prevention of DR because it helps achieve good glycaemic control and improves retinal blood flow and the vascular tone of retinal microvasculature [41]. Joint conclusions from various studies, depending on the type of diabetes, agree that intensive glycaemic control from the time of diagnosis of diabetes is beneficial in preventing the onset of DR and in delaying its progression, and an $\mathrm{HbA}_{1 \mathrm{c}}$ level of $<7 \%$ is recommended [34]. Laser retinal photocoagulation is a recognised treatment method for DR. It is used to destroy areas of ischaemia in the retina and hard exudates [42]. Many randomised control trials demonstrated the benefit of panretinal photocoagulation (PRP) and focal/grid macular laser therapy [43]. The standard treatment in PDR is PRP, which is effective but has established side effects such as peripheral visual-field constraints [44]. Surgical treatment in the course of ophthalmological complications is represented mainly by vitrectomy [45]. Drugs target- ing VEGF (anti-VEGF) have been studied extensively in diabetic macular oedema (DMO), and results have shown regression of DR with anti-VEGF treatment [46]. Recent studies have shown that anti-VEGF is not inferior to PRP for PDR while treatment is maintained, although the recurrence rate when anti-VEGF treatment is stopped is unclear [44]. In vitreous haemorrhage, where PRP cannot be performed, use of anti-VEGF medications can treat underlying PDR and delay or reduce the need for vitrectomy. However, anti-VEGF treatment requires careful patient selection and monitoring [44].

\section{Thyroid dysfunction in patients with diabetes}

Thyroid disease and DM are the two most common endocrinopathies occurring in clinical practice $[1,2]$. DM and thyroid dysfunction have a mutual influence: on the one hand, thyroid hormones regulate carbohydrate metabolism and pancreas functions, and on the other hand, DM affects thyroid gland function and work [47]. Common pathophysiological connections of thyroid disease and DM are indicated by an increasing number of studies on their biochemical, genetic, and hormonal interactions. It was first stated in the NHANES III study that thyroid disease was more common in patients with DM than in the non-DM population. Examining patients with DM, Perros et al. showed a general incidence of thyroid disease at $13.4 \%$ in this group, with women 
with type $1 \mathrm{DM}(31.4 \%)$ noted most often, and men with type 2 DM most rarely (6.9\%) [48]. Other studies have shown that the incidence of thyroid disease ranges from $4.8 \%$ to $31.4 \%[49,50]$. The causes that can cause such large differences in test results include various diagnostic criteria for thyroid dysfunction, a different degree of iodine intake between different regions, different sensitivity of TSH detection tests, and a large variety of populations tested [51]. Thyroid dysfunction has been found to occur more often in people with type $1 \mathrm{DM}$ compared to type $2 \mathrm{DM}$, and the incidence of AITD in patients with type $1 \mathrm{DM}$ varies from 3 to $50 \%$ [52]. In addition, in patients with positive IgG antibodies (antibodies to glutamic acid decarboxylase, anti-GAD), a 3.5-fold increased risk of HT has been noted [53]. The most recent meta-analysis performed on all available data of 10,920 patients with DM showed an average frequency of thyroid disease of $11 \%$, with no difference between type 1 DM and type 2 DM [54]. In the HUNT 2 study it was established that autoimmune DM was associated with a higher age-corrected occurrence of hypothyroidism in both women (prevalence rate 1.79) and men (prevalence rate 2.71) compared to the absence of DM [55]. Positive aTPO was shown in $38 \%$ of people with DM who subsequently developed full-blown or subclinical hypothyroidism (SCH) $[56,57,58]$. Based on a meta-analysis, Chang et al. determined that the incidence of $\mathrm{SCH}$ in patients with type $2 \mathrm{DM}$ was $10.2 \%$, while type $2 \mathrm{DM}$ was associated with a 1.93 -fold increase in SCH (95\% CI: 1.66-2.24) [55]. Palma et al. showed in their study that $\mathrm{SCH}$ was the most common thyroid dysfunction observed, appearing in $11.8 \%$ of patients, and it was more common in this group than in people without DM [52]. Thyroid hormones affect glucose metabolism through several mechanisms, which are shown in Figure 2 and 3 [47].

In people with euthyroid disease with DM, the levels of triiodothyronine (T3), TSH, and thyrotropin-releasing hormone (TRH) are subject to glycaemic changes in two major areas. Glycaemia is involved in the regulation of the hypothalamic-pituitary-thyroid axis feedback and TSH release from the hypothalamus; it also affects conversion of thyroxine (T4) to T3 in peripheral tissues. Nocturnal TSH peak and TSH response to TRH are impaired in DM patients [59-61]. Reduced T3 levels that normalise with improved glycaemic control have been seen in patients with decompensated DM. Higher plasma insulin levels associated with insulin resistance (IR) act pro-proliferatively on the thyroid gland, which in consequence may lead to tuberous goitre. Coexisting DM may also affect the efficacy of hypothyroid substitution treatment with levothyroxine $[62,63]$. Unrecognised thyroid dysfunction may affect DM metabolic control. Interactions between thyroid hormones and mechanisms controlling appetite, energy expenditure, and insulin sensitivity are also important. A better understanding of this multi-faceted relationship between DM and thyroid disease can help optimize

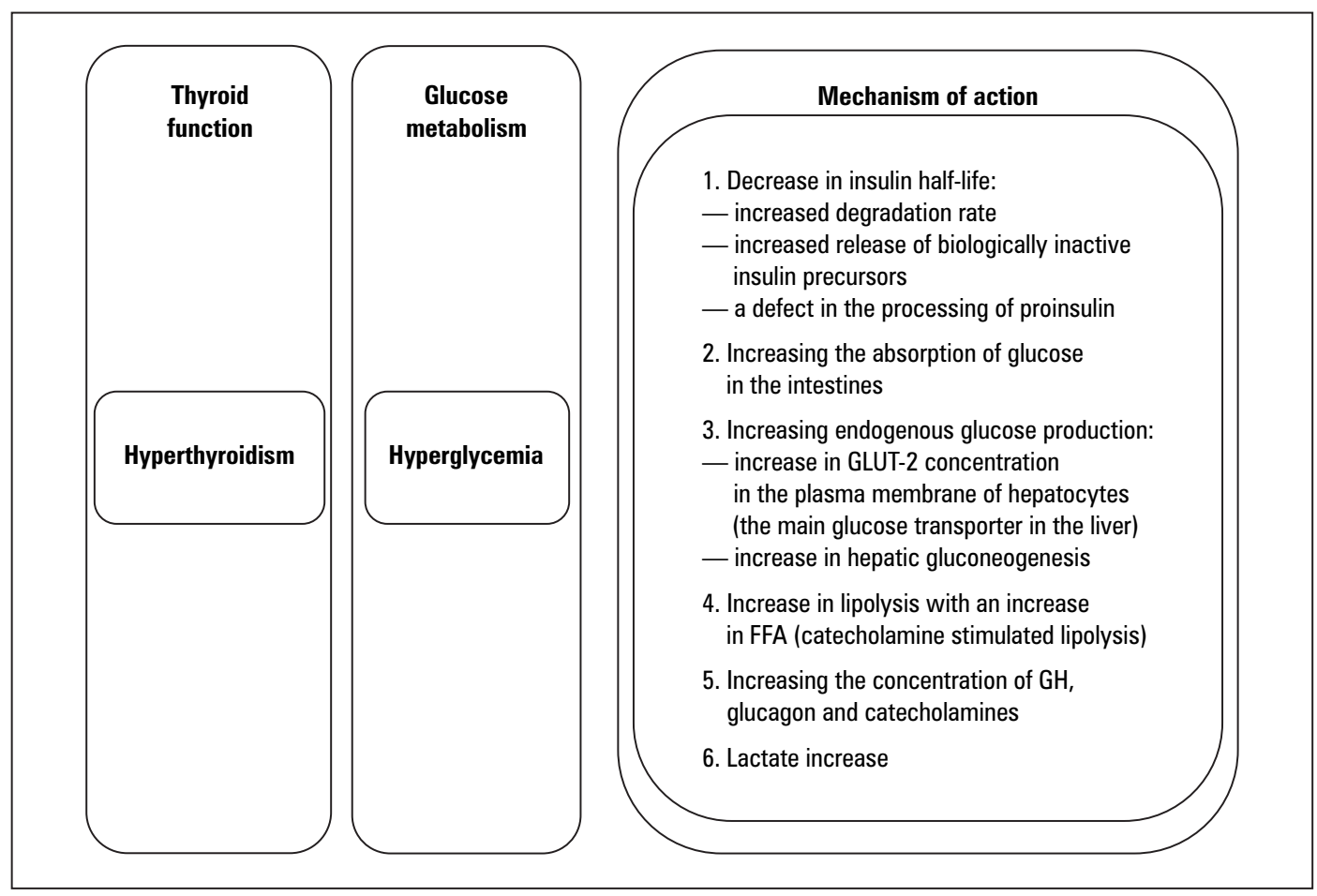

Figure 2. Effect of thyroid hormones on glucose metabolism. FFA — free fatty acids; GH - growth hormone 


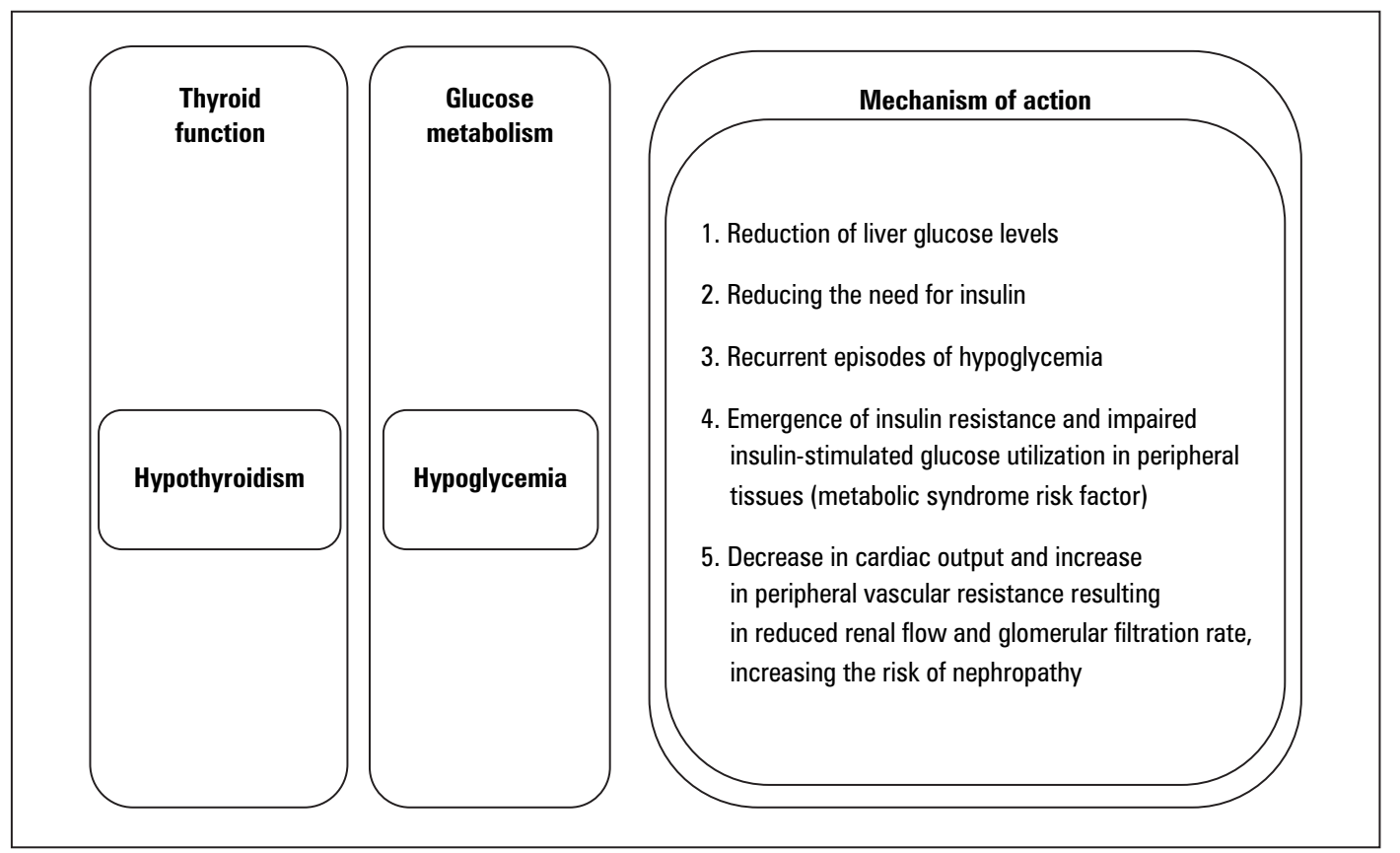

Figure 3. Effect of thyroid hormones on glucose metabolism

the management of patients with DM [51]. Treatment of thyroid dysfunction in DM patients has a beneficial effect on glycaemic control, reduces cardiovascular risk, and improves patients' overall well-being [64].

\section{Thyroid dysfunction in patients with diabetic retinopathy}

There are few reports in the literature regarding the impact of thyroid disease on the development and course of DR. The hypothalamic-pituitary-thyroid axis plays an important role in retinal development and contributes to the increase in retinal vascular density $[65,66]$. Most research on this topic is based on animal models. During the morphometric analysis of rats in which hypothyroidism was induced, Pinazo-Durán et al. showed a decrease in eyeball volume and thinning of the retinal layers. Reduced transverse dimension and retardation of optic nerve myelination were also found in rats with hypothyroidism compared to the control group [67]. In rats with induced hypothyroidism, Kocaturka et al. showed a lower level of sirtuin 2 (SIRT-2) protein in the retinal ganglion cell layer, which indicates a significant influence of thyroid hormones on the normal development of retinal cytoarchitecture [68]. During studies on rats with DM and retinal microangiopathy, recognised as thickening of the basement membrane of the capillaries, it was found that the concentration of $\mathrm{T} 4$ in rat plasma decreased after eight months, and the same of T3 after eight and 12 months, compared to the control group [69]. It was proven that rats with induced DM and T4 deficiency have altered vascular reactivity, which is reversible with T4 supplementation [70]. Relationships in symptoms among patients with thyroid disease have also been demonstrated in patients with DR. These are often factors that contribute to the pathogenesis of DR in patients with DM. What is interesting is the relationship between thyroid disease and retinal blood flow. Ittermann et al. observed in their study that in the group of patients with a higher TSH concentration, the arteriovenous index was lower and the retinal arterial vessels were narrower than in those with euthyroid disease. Arterial vasoconstriction can be caused by microvascular damage secondary to local hypertension, atherosclerosis, and inflammation [71]. In DR, chronic inflammation occurs that causes damage to the vascular endothelium. Czarnywojtek et al. showed that in patients with thyroid disease, both in hyperthyroidism and hypothyroidism, serum CRP levels increase. It can be assumed that thyroid dysfunction can lead to systemic inflammation [72]. Christa-Crain et al. and Kvetny et al. showed an interesting relationship in the study of patients with $\mathrm{SCH}$, who had significantly higher CRP concentration in serum than people without $\mathrm{SCH}$ [55]. Iitaka et al. observed elevated serum VEGF levels in patients with untreated GD and HT, which positively correlated with the degree of thyroid vascularisation. VEGF C and Flt- 4 were also localised in human tissues of goitre and AITD. Lymphocytic thyroiditis and differentiated thyroid cancers are more strongly expressed by VEGF than healthy gland tissues $[73,74]$. Increased 
levels of VEGF expression are already observed in the early stages of DR [29]. Patients with hypothyroidism have an IR, a condition in which there is an elevated concentration of plasminogen activator inhibitor-1 (PAI-1), belonging to the group of fibrinolysis inhibitors. Defective fibrinolysis or impaired IR-associated vasodilatation may be correlated with decreased vasodilatability and secondary fibrosis, which leads to retinal vascular destruction and secondary revascularisation in DR [55]. Thyroid dysfunction significantly affects changes in lipid profile [75]. Dyslipidaemia was more frequent in patients with DR than in the control group [76]. Dyslipidaemia may affect the occurrence of DR in patients with thyroid dysfunction. In the pathogenesis of autoimmune thyroid disease and DR, oxidative stress appears to be an important risk factor that has a negative impact on the morphology and functioning of the retina. Higher activity of malondialdehyde (MDA) and lower activity of paraoxonase 1 (PON1) was demonstrated in the plasma of patients with hypothyroidism [77]. Looker et al. showed that higher serum homocysteine concentration is a risk factor for DR, and homocysteine may increase lipid peroxidation, which leads to increased levels of low-density oxidised lipoprotein (oxLDL), accelerating the progression of vascular disease [55]. To date, little research has been done into the effects of thyroid disease on the development of DR in patients with type $1 \mathrm{DM}$. Literature analysis of the occurrence of DR in patients with type $1 \mathrm{DM}$, however, shows a significant impact of thyroid disease on the development of DR. Examining the population of patients with type $1 \mathrm{DM}$ in Brazil, Rodacki et al. proved that TSH levels at $0.4-2.5 \mathrm{mU} / \mathrm{L}$ are associated with a lower risk of DR and renal failure in people with type $1 \mathrm{DM}$, regardless of glycaemia control and disease duration [78]. Quite unexpectedly, Rogowicz-Frontczak A. et al. showed in their study that patients with type $1 \mathrm{DM}$ and positive aTPO, aTg, or TRAb antibodies develop less microangiopathy compared to the group without AITD. They were the first to indicate that DR was less common among patients with type $1 \mathrm{DM}$ and AITD [79]. Probably the genetic profile of patients with autoimmune polyglandular syndrome has a protective effect on the development of DR, despite the higher risk of overt thyroid disease and other organ-specific disorders [80]. The effect of thyroid preparations on DR was previously studied by Schneider et al. in 19 patients with type $1 \mathrm{DM}$ for two years. Twelve out of 19 cases showed improvement in thyroid preparations with a reduction in haemorrhage and exudate, but these results have not been confirmed in a larger population [81]. There are few studies in the literature that have shown a link between hypothyroidism and DR in patients with type $2 \mathrm{DM}$. Sailesh S. et al. demon- strated that patients with type $2 \mathrm{DM}$ and concomitant hypothyroidism (during treatment with levothyroxine) are exposed to a significantly lower risk of developing DR. The exact mechanism of this effect is unknown and requires further investigation. In these patients, the protective effect against DR was found even though the patients were older and had higher systolic blood pressure than the control group [82]. Few observations relate to the occurrence of $\mathrm{DR}$ in the population of SCH patients with type $2 \mathrm{DM}$. A meta-analysis of all published epidemiological studies on DR and $\mathrm{SCH}$ conducted by Wu et al. showed that SCH was associated with DR, and exposure to SCH may increase the risk of developing DR by 2.13 fold [83]. This was also confirmed by recent studies by Borooah et al., who showed that a more severe form of DR was diagnosed in patients with SCH compared to patients with euthyroid disease. The severity of DR increases significantly with the increase of serum TSH concentration [84]. Therefore, patients with $\mathrm{SCH}$ should undergo frequent eye examinations to rule out DR. To date, no reasons have been established for this phenomenon.Coexistence of DM with thyroid disease leads to endothelial damage. The degree of endothelial dysfunction has a significant impact on the course of macro- and microangiopathic complications in patients with DM. However, there is a lack of large-scale research on the impact of thyroid disorders on the occurrence and course of chronic complications of DM, including DR. Factors that have a protective effect on the occurrence of DR include good metabolic control of DM, early detection and treatment of hypertension and dyslipidaemia, maintenance of normal weight, and cessation of smoking [85]. Patients with DM have thyroid homeostasis disorders that depend on the degree of metabolic control. However, improving DM control does not appear to affect T4 levels or the hypothalamic-pituitary-thyroid axis, which may explain why some patients develop DR despite good control and vice versa. Disruption of thyroid hormone homeostasis may contribute to a higher incidence of DR in patients with hypothyroidism due to the fact they are not treated with levothyroxine preparations.

\section{Conclusion}

Our literature analysis draws attention to an important clinical problem, which is progressive vision loss in patients with DM and connections in the discussed area, among others the effect of thyroid disease and levothyroxine substitution on the development and course of DR in patients with DM. Having presented all the above facts, it is necessary to emphasise that early detection and monitoring of thyroid dysfunction in DM is extremely important and can contribute to stop 
appearance the complications of DM patients. This may help prevent blindness and improve the quality of life for patients with DM.

\section{References}

1. Mamun M, Nahar N, Salekin M, et al. Thyroid Hormonal Status in Newly Diagnosed Type 2 Diabetes Mellitus. Bangl J Nucl Med. 2018; 20: 1-27, doi: 10.3329/bjnm.v20i1.36851.

2. Nishi M. Diabetes mellitus and thyroid diseases. Diabetol Int. 2018; 9(2): 108-112, doi: 10.1007/s13340-018-0352-4, indexed in Pubmed: 30603357 .

3. Donckier JE. Endocrine diseases and diabetes. In: Pickup JC, Williams G. ed. Diabetes Mellitus. Blackwell Publishing Company, Chichester 2003: 21-27.

4. Biondi B, Kahaly GJ, Robertson RP. Thyroid Dysfunction and Diabetes Mellitus: Two Closely Associated Disorders. Endocr Rev. 2019; 40(3): 789-824, doi: 10.1210/er.2018-00163, indexed in Pubmed: 30649221.

5. Chutia $\mathrm{H}$, Bhattacharyya $\mathrm{H}$, Ruram AA, et al. Evaluation of thyroid function in type 2 diabetes in north-eastern part of India: A hospital-based study. J Family Med Prim Care. 2018; 7(4): 752-755, doi: 10.4103/jfmpc. jfmpc 292 17, indexed in Pubmed: 30234048.

6. Chawla A, Chawla R, Jaggi S. Microvasular and macrovascular complications in diabetes mellitus: Distinct or continuum? Indian J Endocrinol Metab. 2016; 20(4): 546-551, doi: 10.4103/2230-8210.183480, indexed in Pubmed: 27366724

7. Solomon SD, Chew E, Duh EJ, et al. Diabetic Retinopathy: A Position Statement by the American Diabetes Association. Diabetes Care. 2017; 40(3): 412-418, doi: 10.2337/dc16-2641, indexed in Pubmed: 28223445.

8. Zalecenia kliniczne dotyczące postępowania u chorych na cukrzycę Stanowisko Polskiego Towarzystwa Diabetologicznego. Diabetologia Praktyczna. 2018; 4(1): 1-94.

9. Sheldon J. Laboratory testing in autoimmune rheumatic diseases. Best Pract Res Clin Rheumatol. 2004; 18(3): 249-269, doi: 10.1016/j. berh.2004.03.007, indexed in Pubmed: 15158740.

10. McCoy L, Tsunoda I, Fujinami RS. Multiple sclerosis and virus induced immune responses: autoimmunity can be primed by molecular mimicry and augmented by bystander activation. Autoimmunity. 2006; 39(1): 9-19, doi: 10.1080/08916930500484799, indexed in Pubmed: 16455578

11. Guilherme L, Kalil J. Rheumatic fever: the T cell response leading to autoimmune aggression in the heart. Autoimmun Rev. 2002; 1(5): 261-266, doi: 10.1016/s1568-9972(02)00062-9, indexed in Pubmed: 12848978.

12. Hayter SM, Cook MC. Updated assessment of the prevalence, spectrum and case definition of autoimmune disease. Autoimmun Rev. 2012; 11(10): 754-765, doi: 10.1016/j.autrev.2012.02.001, indexed in Pubmed: 22387972

13. Sfriso P, Ghirardello A, Botsios C, et al. Infections and autoimmunity: the multifaceted relationship. J Leukoc Biol. 2010; 87(3): 385-395, doi: 10.1189/jlb.0709517, indexed in Pubmed: 20015961.

14. Desai MK, Brinton RD. Autoimmune Disease in Women: Endocrine Transition and Risk Across the Lifespan. Front Endocrinol (Lausanne). 2019; 10: 265, doi: 10.3389/fendo.2019.00265, indexed in Pubmed: 31110493.

15. Golden SH, Robinson KA, Saldanha I, et al Clinical review: Prevalence and incidence of endocrine and metabolic disorders in the United States: a comprehensive review. J Clin Endocrinol Metab. 2009; 94(6): 1853-1878, doi: 10.1210/jc.2008-2291, indexed in Pubmed: 19494161.

16. Iddah MA, Macharia BN. Autoimmune thyroid disorders. ISRN Endocrinol. 2013; 2013: 509764, doi: 10.1155/2013/509764, indexed in Pubmed: 23878745.

17. Sawicka-Gutaj N, Zybek-Kocik A, Klimowicz A, et al. Circulating Visfatin in Hypothyroidism Is Associated with Free Thyroid Hormones and Antithyroperoxidase Antibodies. Int J Endocrinol. 2016; 2016: 7402469, doi: 10.1155/2016/7402469, indexed in Pubmed: 26884761

18. Delemer B, Aubert JP, Nys P, et al. An observational study of the initial management of hypothyroidism in France: the ORCHIDÉE study. Eur J Endocrinol. 2012; 167(6): 817-823, doi: 10.1530/EJE-11-1041, indexed in Pubmed: 23034782.

19. Caturegli P, De Remigis A, Rose NR. Hashimoto thyroiditis: clinical and diagnostic criteria. Autoimmun Rev. 2014; 13(4-5): 391-397, doi: 10.1016/j. autrev.2014.01.007, indexed in Pubmed: 24434360.

20. Bloodworth J. Diabetic retinopathy. Diabetes. 1962; 11: 1-22, indexed in Pubmed: 13870120.

21. Wolter JR. Diabetic retinopathy. Am J Ophthalmol. 1961; 51: 1123-1141, doi: 10.1016/0002-9394(61)91802-5, indexed in Pubmed: 13786453

22. Cunha-Vaz J. Neurodegeneration as an early event in the pathogenesis of Diabetic Retinopathy: A multicentric, prospective, phase II-III, randomised controlled trial to assess the efficacy of neuroprotective drugs administered topically to prevent or arrest Diabetic Rethinopathy. EUROCONDOR — EU FP7 Project. Acta Ophthalmol. 2012; 90(249): 0-0, doi: 10.1111/j.1755-3768.2012.2825.x.
23. Antonetti DA, Klein R, Gardner TW. Diabetic retinopathy. N Engl J Med. 2012; 366(13): 1227-1239, doi: 10.1056/NEJMra1005073, indexed in Pubmed: 22455417

24. Cunha-Vaz J, Ribeiro L, Lobo C. Phenotypes and biomarkers of diabetic retinopathy. Prog Retin Eye Res. 2014; 41: 90-111, doi: 10.1016/j.preteyeres.2014.03.003, indexed in Pubmed: 24680929.

25. Ratajczak W, Tokarz-Deptuła B, Deptuła W. Immunologia oka. Postepy Hig Med Dosw (online). 2018; 72: 318-325.

26. Abcouwer SF, Gardner TW. Diabetic retinopathy: loss of neuroretinal adaptation to the diabetic metabolic environment. Ann NY Acad Sci. 2014 1311: 174-190, doi: 10.1111/nyas.12412, indexed in Pubmed: 24673341.

27. Sohn EH, van Dijk HW, Jiao C, et al. Retinal neurodegeneration may precede microvascular changes characteristic of diabetic retinopathy in diabetes mellitus. Proc Natl Acad Sci USA. 2016; 113(19): E2655-E2664, doi: 10.1073/pnas.1522014113, indexed in Pubmed: 27114552.

28. Eshaq RS, Aldalati AMZ, Alexander JS, et al. Diabetic retinopathy: Breaking the barrier. Pathophysiology. 2017; 24(4): 229-241, doi: 10.1016/j. pathophys.2017.07.001, indexed in Pubmed: 28732591.

29. Rusin P, Majsterek I. Molekularne podstawy retinopatii cukrzycowej Postępy Hig. Med. Dośw. (online). 2007; 61: 786-796.

30. Yau JWY, Rogers SL, Kawasaki R, et al. Meta-Analysis for Eye Disease (META-EYE) Study Group. Global prevalence and major risk factors of diabetic retinopathy. Diabetes Care. 2012; 35(3): 556-564, doi: 10.2337/dc11-1909, indexed in Pubmed: 22301125.

31. Kollias AN, Ulbig MW. Diabetic retinopathy: Early diagnosis and effective treatment. Dtsch Arztebl Int. 2010; 107(5): 75-83; quiz 84, doi: 10.3238/arztebl.2010.0075, indexed in Pubmed: 20186318.

32. Wu L, Fernandez-Loaiza P, Sauma J, et al. Classification of diabetic retinopathy and diabetic macular edema. World J Diabetes. 2013; 4(6): 290-294, doi: 10.4239/wjd.v4.i6.290, indexed in Pubmed: 24379919.

33. Fong DS, Aiello L, Gardner TW, et al. Diabetic Retinopathy. Diabetes Care. 2003; 26(Supplement 1): S99-S102, doi: 10.2337/diacare.26.2007. s99, indexed in Pubmed: 12502630 .

34. Rajalakshmi R, Prathiba V, Mohan V. Does tight control of systemic factors help in the management of diabetic retinopathy? Indian J Ophthalmol. 2016; 64(1): 62-68, doi: 10.4103/0301-4738.178146, indexed in Pubmed: 26953026

35. Pradeepa R, Anitha B, Mohan V, et al. Risk factors for diabetic retinopathy in a South Indian Type 2 diabetic population - the Chennai Urban Rural Epidemiology Study (CURES) Eye Study 4. Diabet Med. 2008; 25(5): 536-542, doi: 10.1111/j.1464-5491.2008.02423.x, indexed in Pubmed: 18346159

36. Shichiri M, Kishikawa H, Ohkubo Y, et al. Long-term results of the Kumamoto Study on optimal diabetes control in type 2 diabetic patients. Diabetes Care. 2000; 23(Suppl 2): B21-B29, indexed in Pubmed: 10860187.

37. Chew EY, Ambrosius WT, Davis MD, et al. ACCORD Study Group, ACCORD Eye Study Group. Effects of medical therapies on retinopathy progression in type 2 diabetes. N Engl J Med. 2010; 363(3): 233-244, doi: 10.1056/NEJMoa1001288, indexed in Pubmed: 20587587

38. Nathan DM, Genuth S, Lachin J, et al. Diabetes Control and Complications Trial Research Group. The effect of intensive treatment of diabetes on the development and progression of long-term complications in insulin-dependent diabetes mellitus. N Engl J Med. 1993; 329(14): 977-986, doi: 10.1056/NEJM199309303291401, indexed in Pubmed: 8366922.

39. Intensive blood-glucose control with sulphonylureas or insulin compared with conventional treatment and risk of complications in patients with type 2 diabetes (UKPDS 33). UK Prospective Diabetes Study (UKPDS) Group. Lancet. 1998; 352(9131): 837-853, indexed in Pubmed: 9742976.

40. Matuszewski W, Bandurska-Stankiewicz E, Modzelewski R, et al. Diagnosis and treatment of diabetic retinopathy - historical overview. Clin Diab. 2017; 6(5): 182-188, doi: 10.5603/dk.2017.0030.

41. Silva PS, Cavallerano JD, Sun JK, et al. Effect of systemic medications on onset and progression of diabetic retinopathy. Nat Rev Endocrinol. 2010; 6(9): 494-508, doi: 10.1038/nrendo.2010.122, indexed in Pubmed: 20664533

42. Kozak I, Luttrull JK. Modern retinal laser therapy. Saudi J Ophthalmol. 2015; 29(2): 137-146, doi: 10.1016/j.sjopt.2014.09.001, indexed in Pubmed: 25892934

43. Yun SH, Adelman RA. Recent developments in laser treatment of diabetic retinopathy. Middle East Afr J Ophthalmol. 2015; 22(2): 157-163, doi: 10.4103/0974-9233.150633, indexed in Pubmed: 25949072.

44. Zhao Y, Singh RP. The role of anti-vascular endothelial growth factor (anti-VEGF) in the management of proliferative diabetic retinopathy. Drugs Context. 2018; 7: 212532, doi: 10.7573/dic.212532, indexed in Pubmed: 30181760.

45. Brănişteanu DC, Bilha A, Moraru A. Vitrectomy surgery of diabetic retinopathy complications. Rom J Ophthalmol. 2016; 60(1): 31-36, indexed in Pubmed: 27220230.

46. Papadopoulos N, Martin J, Ruan Q, et al. Binding and neutralization of vascular endothelial growth factor (VEGF) and related ligands by 
VEGF Trap, ranibizumab and bevacizumab. Angiogenesis. 2012; 15(2): 171-185, doi: 10.1007/s10456-011-9249-6, indexed in Pubmed: 22302382

47. Hage M, Zantout MS, Azar ST. Thyroid disorders and diabetes mellitus. J Thyroid Res. 2011; 2011: 439463, doi: 10.4061/2011/439463, indexed in Pubmed: 21785689.

48. Perros P, McCrimmon RJ, Shaw G, et al. Frequency of thyroid dysfunction in diabetic patients: value of annual screening. Diabet Med. 1995 12(7): 622-627, doi: 10.1111/j.1464-5491.1995.tb00553.x, indexed in Pubmed: 7554786 .

49. Hansen D, Bennedbaek FN, Hansen LK, et al. Thyroid function, morphology and autoimmunity in young patients with insulin-dependent diabetes mellitus. Eur J Endocrinol. 1999; 140(6): 512-518, doi: 10.1530/eje.0.1400512, indexed in Pubmed: 10366407.

50. Celani MF, Bonati ME, Stucci N. Prevalence of abnormal thyrotropin concentrations measured by a sensitive assay in patients with type 2 diabetes mellitus. Diabetes Res. 1994; 27(1): 15-25, indexed in Pubmed: 7648793

51. Ray S, Ghosh S. Thyroid Disorders and Diabetes Mellitus: Double Trouble . J Dia Res Ther. 2016; 2(1), doi: 10.16966/2380-5544.113.

52. Palma CC, Pavesi M, Nogueira VG, et al. Prevalence of thyroid dysfunction in patients with diabetes mellitus. Diabetol Metab Syndr. 2013; 5(1): 58, doi: 10.1186/1758-5996-5-58, indexed in Pubmed: 24499529.

53. Kordonouri O, Charpentier N, Hartmann R. GADA positivity at onset of type 1 diabetes is a risk factor for the development of autoimmune thyroiditis. Pediatr Diabetes. 2011; 12(1): 31-33, doi: 10.1111/j.1399-5448 .2010.00666.x, indexed in Pubmed: 20723098.

54. Kadiyala R, Peter R, Okosieme OE. Thyroid dysfunction in patients with diabetes: clinical implications and screening strategies. Int J Clin Pract. 2010; 64(8): 1130-1139, doi: 10.1111/j.1742-1241.2010.02376.x, indexed in Pubmed: 20642711.

55. Ahmed A, Waris A, Naheed A, et al. Diabetic Retinopathy and its Correlation with Thyroid Profile and Anti Thyroid Antibodies. IOSR-JDMS. 2017; 16(1): 96-98, doi: 10.9790/0853-1601079698

56. Kordonouri O, Deiss D, Danne T, et al. Predictivity of thyroid autoantibodies for the development of thyroid disorders in children and adolescents with Type 1 diabetes. Diabet Med. 2002; 19(6): 518-521, do : 10.1046/j.1464-5491.2002.00699.x, indexed in Pubmed: 12060066.

57. Kordonouri O, Hartmann R, Deiss D, et al. Natural course of autoimmune thyroiditis in type 1 diabetes: association with gender, age, diabetes duration, and puberty. Arch Dis Child. 2005; 90(4): 411-414, doi: 10.1136/adc.2004.056424, indexed in Pubmed: 15781936.

58. Lindberg B, Ericsson UB, Ljung R, et al. High prevalence of thyroid autoantibodies at diagnosis of insulin-dependent diabetes mellitus in Swedish children. J Lab Clin Med. 1997; 130(6): 585-589, doi: 10.1016/s0022-2143(97)90108-6, indexed in Pubmed: 9422332.

59. Gursoy NT, Tuncel E. The relationship between the glycemic control and the hypothalamus-pituitary-thyroid axis in diabetic patients. Turk J Endocrinol Metab. 1999; 4: 163-168.

60. Ortiz-Caro J, Obregón MJ, Pascual A, et al. Decreased T4 to T3 conversion in tissues of streptozotocin-diabetic rats. Acta Endocrino (Copenh). 1984; 106(1): 86-91, doi: 10.1530/acta.0.1060086, indexed in Pubmed: 6328820

61. Bagchi N, Palaniswami N, Desai H, et al. Decreased thyroidal response to thyrotropin in type II diabetes mellitus. Metabolism. 1988; 37(7) 669-671, doi: 10.1016/0026-0495(88)90088-1, indexed in Pubmed: 3133539

62. Rezzonico J, Rezzonico M, Pusiol E et al Introducing the thyroid gland as another victim of the insulin resistance syndrome. Thyroid. 2008; 18(4): 461-464, doi: 10.1089/thy.2007.0223, indexed in Pubmed: 18346005 .

63. Ayturk S, Gursoy A, Kut A, et al. Metabolic syndrome and its components are associated with increased thyroid volume and nodule prevalence in a mild-to-moderate iodine-deficient area. Eur J Endocrinol. 2009; 161(4): 599-605, doi: 10.1530/EJE-09-0410, indexed in Pubmed: 19633072

64. Chutia H, Bhattacharyya H, Ruram AA, et al. Evaluation of thyroid function in type 2 diabetes in north-eastern part of India: A hospital-based study. J Family Med Prim Care. 2018; 7(4): 752-755, doi: 10.4103/jfmpc. jfmpc_292_17, indexed in Pubmed: 30234048.

65. Martino E, Seo H, Lernmark A, et al. Ontogenetic patterns of thyrotropin-releasing hormone-like material in rat hypothalamus, pancreas, and retina: selective effect of light deprivation. Proc Natl Acad Sci USA. 1980; 77(7): 4345-4348, doi: 10.1073/pnas.77.7.4345, indexed in Pubmed: 6776526
66. Mendoza A, Hollenberg AN. New insights into thyroid hormone action. Pharmacol Ther. 2017; 173: 135-145, doi: 10.1016/j.pharmthera.2017.02.012, indexed in Pubmed: 28174093.

67. Pinazo-Durán MD, Pons-Vázquez S, Gallego-Pinazo R, et al. Thyroid hormone deficiency disrupts rat eye neurodevelopment. Brain Res. 2011; 1392: 16-26, doi: 10.1016/j.brainres.2011.04.005, indexed in Pubmed: 21529787.

68. Kocaturk T, Ergin K, Cesur G, et al. The effect of methimazole-induced postnatal hypothyroidism on the retinal maturation and on the Sirtuin 2 level. Cutan Ocul Toxicol. 2016; 35(1): 36-40, doi: 10.3109/15569527.20 15.1007509, indexed in Pubmed: 25758293.

69. Waber S, Meister V, Rossi GL, et al. Studies on retinal microangiopathy and coronary macroangiopathy in rats with streptozotocin-induced diabetes. Virchows Arch B Cell Pathol Incl Mol Pathol. 1981; 37(1): 1-10, doi: 10.1007/bf02892551, indexed in Pubmed: 6116344

70. Takiguchi Y, Satoh N, Hashimoto H, et al. Reversal effect of thyroxine on altered vascular reactivity in diabetic rats. J Cardiovasc Pharmacol. 1989; 13(4): 520-524, indexed in Pubmed: 2470987.

71. Ittermann T, Dörr M, Völzke H, et al. High serum thyrotropin levels are associated with retinal arteriolar narrowing in the general population. Thyroid. 2014; 24(10): 1473-1478, doi: 10.1089/thy.2014.0190, indexed in Pubmed: 25156414

72. Czarnywojtek A, Owecki M, Zgorzalewicz-Stachowiak M, et al. The role of serum C-reactive protein measured by high-sensitive method in thyroid disease. Arch Immunol Ther Exp (Warsz). 2014; 62(6): 501-509, doi: 10.1007/s00005-014-0282-1, indexed in Pubmed: 24794233.

73. Iitaka M, Miura S, Yamanaka K, et al. Increased serum vascular endothelial growth factor levels and intrathyroidal vascular area in patients with Graves' disease and Hashimoto's thyroiditis. J Clin Endocrinol Metab. 1998; 83(11): 3908-3912, doi: 10.1210/jcem.83.11.5281, indexed in Pubmed: 9814467.

74. Kajdaniuk D, Marek B, Foltyn W, et al. Vascular endothelial growth factor (VEGF) - part 2: in endocrinology and oncology. Endokrynol Pol. 2011; 62(5): 456-464, indexed in Pubmed: 22069107.

75. Rizos CV, Elisaf MS, Liberopoulos EN. Effects of thyroid dysfunction on lipid profile. Open Cardiovasc Med J. 2011; 5: 76-84, doi: 10.2174/18741 92401105010076, indexed in Pubmed: 21660244

76. Popescu T, Mota M. Dyslipidemia and hypertension in patients with type 2 diabetes and retinopathy. Rom J Intern Med. 2009; 47(3): 235-241, indexed in Pubmed: 20446438

77. Baskol G, Atmaca H, Tanriverdi $F$, et al. Oxidative stress and enzymatic antioxidant status in patients with hypothyroidism before and after treatment. Exp Clin Endocrinol Diabetes. 2007; 115(8): 522-526, doi: 10.1055/s-2007-981457, indexed in Pubmed: 17853336

78. Rodacki M, Zajdenverg L, Dantas JR, et al. Should thyroid-stimulating hormone goals be reviewed in patients with type 1 diabetes mellitus? Results from the Brazilian Type 1 Diabetes Study Group. Diabet Med. 2014 31(12): 1665-1672 doi: 10.1111/dme 12530, indexed in Pubmed: 24961827.

79. Rogowicz-Frontczak A, Pilacinski S, Chwialkowska AT, et al. Patients with diabetes type 1 and thyroid autoimmunity have low prevalence of microangiopathic complications. Endocrine. 2016; 51(1): 185-188, doi: 10.1007/s12020-015-0643-5, indexed in Pubmed: 26044140.

80. Glastras SJ, Craig ME, Verge CF, et al. The role of autoimmunity at diagnosis of type 1 diabetes in the development of thyroid and celiac disease and microvascular complications. Diabetes Care. 2005; 28(9): 2170-2175, doi: 10.2337/diacare.28.9.2170, indexed in Pubmed: 16123485

81. Schneider T, Meyerson L. Thyroid therapy in diabetic retinopathy. S Afr Med J. 1969; 43(14): 414-417, indexed in Pubmed: 5786233.

82. Sailesh S. The THOR Effect: Thyroid Hormone Offsets Retinopathy. J Endocrinol Thyroid Res. 2018; 3(1): 555605, doi: 10.19080/jetr.2018.03.555605.

83. Wu J, Yue S, Geng J, et al. Relationship between Diabetic Retinopathy and Subclinical Hypothyroidism: a meta-analysis. Sci Rep. 2015; 5: 12212 , doi: 10.1038/srep12212, indexed in Pubmed: 26193340.

84. Borooah M, Phukan S. A study on relationship between severity of diabetic retinopathy and subclinical hypothyroidism. Int J Res Med Sci. 2017; 5(5): 1818-1822.

85. Porta M, Sjoelie AK, Chaturvedi N, et al. EURODIAB Prospective Complications Study Group. Risk factors for progression to proliferative diabetic retinopathy in the EURODIAB Prospective Complication Study. Diabetologia. 2001; 44(12): 2203-2209, doi: 10.1007/s001250100030, indexed in Pubmed: 11793022 